\title{
How Smoking Cessation Influence Hormonal Levels in Postmenopausal Women?
}

\author{
Hana Jandíková1, Michaela Dušková', Kateřina Šimůnková1, \\ Beáta Rácz', Martin Hill', Hana Pospíšilová ${ }^{1}$, Alexandra Kmet'ová2,3, \\ Eva Králíkováa ${ }^{2,3}$, Karel Vondra' ${ }^{1}$, Luboslav Stárka ${ }^{1}$ \\ ${ }^{1}$ Institute of Endocrinology, Prague, Czech Republic; \\ ${ }^{2}$ Institute of Hygiene and Epidemiology, First Faculty of Medicine, Charles University \\ in Prague and General University Hospital in Prague, Prague, Czech Republic; \\ ${ }^{3}$ Tobacco Addiction Center, $3^{\text {rd }}$ Department of Medicine - Department of \\ Endocrinology and Metabolism, First Faculty of Medicine, Charles University \\ in Prague and General University Hospital in Prague, Prague, Czech Republic
}

Received January 25, 2014; Accepted April 4, 2014.

Key words: Postmenopause - Smoking cessation - Androgens

Abstract: Smoking represents the most widespread substance dependence in the world. Nicotine alters women hormonal homeostasis. Women smokers have higher testosterone and lower estradiol levels throughout life compared to nonsmokers. We monitored the effect of smoking discontinuation on steroid spectrum with 25 postmenopausal women smokers. They had been examined before discontinuation of smoking and after 6,12, 24 and 48 weeks of abstinence. Blood was collected to determine steroid spectrum (measured by GC-MS), luteinizing hormone, follicle stimulating hormone and sex hormone binding globulin (measured by IRMA). Repeated measures ANOVA model was used for evaluation of the data. In postmenopausal women, an increase in testosterone, dihydrotestosterone, dehydroepiandrosterone and other androgens occurred. Neither nicotine replacement therapy nor weight changes nor age play a role in androgen level increase. The higher androgens levels correlated with failure in smoking cessation. Women smokers have higher androgen levels, which might play a role in smoking dependence development. Women successful in smoking cessation, compared to the non-successful ones, have lower androgen levels initially and also after smoking discontinuation.

This study was supported by grant NT/12340-5 of IGA MZCR, SVV UK 2014 No. 260018 and by MH CZ - DRO (Institute of Endocrinology - EÚ, 00023761).

Mailing Address: Michaela Dušková, MD., PhD., Institute of Endocrinology, Národní 8, 11694 Prague 1, Czech Republic; Phone: +420 224905 280; e-mail: mduskova@endo.cz 


\section{Introduction}

The negative impact of tobacco smoking is complex. However, it influences biosynthesis and steroids effects among others. Smoking interferes with neuroactive steroid metabolism and addiction arises very quickly. Smoking in women has an anti-estrogenic effect. The increase in androgen production in women smokers throughout life from puberty to menopause has been described in studies consistently (Van Voorhis et al., 1992; Barbieri et al., 2005; Manjer et al., 2005; Cochran et al., 2008; Cupisti et al., 2010). However, anti-estrogenic effect has not been confirmed in all studies. A number of studies have focused on the impact of smoking on female reproduction. They have reported increased incidence of infertility in women smokers (Thomford and Mattison, 1986; Weigert et al., 1999). In fertile women, smoking may also influence hormonal contraception effects negatively: this may lead to higher incidence of off-cycle spotting and bleeding (Rosenberg et al., 1996). In postmenopausal women, it appears that even moderate smoking, induces significant changes in hepatic estrogen metabolism. Cassidenti et al. (1990) found alterations in serum estrone sulfate and SHGB-binding capacity that result in decreased serum unbound estradiol. However, these changes do not appear to require increasing the estrogen dosage to achieve physiologic levels of estrogen in postmenopausal smokers (Cassidenti et al., 1990).

\section{Methods}

The study involved 25 postmenopausal women heavy smokers who had decided to stop smoking and sought medical help at the Tobacco Addiction Center.

The women did not use hormonal replacement therapy for at least 6 months before the testing; they did not suffer from any serious illness and did not use any medication affecting steroidogenesis. The women were examined before the initiation of smoking cessation, after 6,12, 24 and 48 weeks of abstinence. During each examination, blood was collected to determine steroid spectrum, luteinizing and follicle stimulating hormones (LH, FSH), sex hormone binding globulin (SHBG) and basic anthropometric data were measured. For evidence of abstinence from smoking, cotinine analysis was used. The study has been approved by the ethics committee of the Institute of Endocrinology. Most of the steroids and their polar conjugates were measured using the previously described GC-MS method (Hill et al., 2010). The 17-hydroxy-pregnenolone was measured by RIA as described in our previous report (Hill et al., 1999) and conjugated 17-hydroxy-pregnenolone was measured using the same method after hydrolysis as described previously. Estradiol was measured by RIA kit from Orion, Finland (intra-assay CV $=4.4 \%$, inter-assay CV $=4.6 \%$ ) and 17-hydroxy-progesterone was assayed by kit from Immunotech, France (intra-assay CV $=5.2 \%$, inter-assay $\mathrm{CV}=6.5 \%$ ). $\mathrm{LH}$ by IRMA kit from Immunotech, France (intra-assay CV $=3.7 \%$, inter-assay $C V=4.3 \%$ ), FSH by IRMA kit from Immunotech, France (intra-assay CV $=2.6 \%$, inter-assay $\mathrm{CV}=4.5 \%$ ) and SHBG by IRMA kit from Orion, Finland (intra-assay $\mathrm{CV}=6.1 \%$, 
inter-assay $C V=7.9 \%)$. The hormonal profiles were evaluated using repeated measures ANOVA model. The statistical software Statgraphics Centurion version XVI from Statpoint Inc. (Warrenton, Virginia, USA) was used for simultaneous data transformations, ANOVA testing and multiple comparisons.

\section{Results}

In the group of postmenopausal women, 10 women were successful in smoking cessation, 15 women failed during the treatment. The average age was $\mathbf{5 7 . 6}$ years ( \pm 6.7 years), average BMI $25.3( \pm 4.2)$. Successful and nonsuccessful women did not differ in age and BMI. The levels of gonadotropins were determined to verify postmenopausal state. The median levels of $\mathrm{LH}$ were $27.9 \mathrm{IU} / \mathrm{l}$ and levels of FSH $48.9 \mathrm{IU} / \mathrm{I}$ in the first sample collection (before the initiation of smoking cessation.) After one year of successful smoking cessation the levels were $28.2 \mathrm{IU} / \mathrm{l}$ and $46.4 \mathrm{IU} / \mathrm{l}$, respectively. We found increasing levels of androgens (testosterone and its metabolites e.g. androsterone, epiandrosterone, dehydroepiandrosterone, 5 -androstene-3 $\beta, 7 \alpha, 17 \beta$-triol) during smoking cessation (Table 1 ). Neither nicotine replacement therapy nor weight changes nor age played a role in androgen level

Table 1 - The effect of smoking cessation and duration of cigarette abstinence on the levels of C21 steroids, estradiol and gonadotropins in postmenopausal chronic smokers

\begin{tabular}{|c|c|c|c|c|}
\hline \multirow[t]{2}{*}{ Variable } & \multicolumn{4}{|c|}{ Week } \\
\hline & 0 & 6 & 12 & 48 \\
\hline $\begin{array}{l}\text { Dehydroepiandro- } \\
\text { sterone }\end{array}$ & $\begin{array}{c}3.06 \\
(2.5,5.02)\end{array}$ & $\begin{array}{c}4.57 \\
(2.63,6.87)\end{array}$ & $\begin{array}{c}5.32 \\
(3.15,6.62)\end{array}$ & $\begin{array}{c}5.76 \\
(3.14,9.96)\end{array}$ \\
\hline $\begin{array}{l}5 \text {-androstene- } 3 \beta \\
7 \alpha, 17 \beta \text {-triol }\end{array}$ & $\begin{array}{c}0.049 \\
(0.0202,0.077)\end{array}$ & $\begin{array}{c}0.065 \\
(0.0255,0.108)\end{array}$ & $\begin{array}{c}0.0962 \\
(0.0436,0.157)\end{array}$ & $\begin{array}{c}0.0739 \\
(0.0479,0.116)\end{array}$ \\
\hline $\begin{array}{l}\text { 5-androstene-3} \beta \text {, } \\
7 \beta, 17 \beta \text {-triol }\end{array}$ & $\begin{array}{c}0.0222 \\
(0.0118,0.0513)\end{array}$ & $\begin{array}{c}0.0335 \\
(0.0138,0.0512)\end{array}$ & $\begin{array}{c}0.0571 \\
(0.0369,0.0747) \\
\end{array}$ & $\begin{array}{c}0.0547 \\
(0.039,0.074)\end{array}$ \\
\hline Testosterone & $\begin{array}{c}0.85 \\
(0.494,1.12) \\
\end{array}$ & $\begin{array}{c}0.666 \\
(0.442,0.99) \\
\end{array}$ & $\begin{array}{c}0.856 \\
(0.632,1.15) \\
\end{array}$ & $\begin{array}{c}1.17 \\
(0.841,1.56) \\
\end{array}$ \\
\hline $\begin{array}{l}\text { Free testosterone } \\
\text { index }\end{array}$ & $\begin{array}{c}1.69 \\
(0.83,3.31)\end{array}$ & $\begin{array}{c}2.1 \\
(1.36,3.57)\end{array}$ & $\begin{array}{c}2.34 \\
(1.53,5.89)\end{array}$ & $\begin{array}{c}2.55 \\
(2.33,3.7)\end{array}$ \\
\hline Androsterone & $\begin{array}{c}0.11 \\
(0.0649,0.156) \\
\end{array}$ & $\begin{array}{c}0.144 \\
(0.0798,0.167) \\
\end{array}$ & $\begin{array}{c}0.105 \\
(0.0987,0.193) \\
\end{array}$ & $\begin{array}{c}0.245 \\
(0.157,0.292) \\
\end{array}$ \\
\hline Epiandrosterone & $\begin{array}{c}0.116 \\
(0.0887,0.216)\end{array}$ & $\begin{array}{c}0.209 \\
(0.132,0.273)\end{array}$ & $\begin{array}{c}0.221 \\
(0.121,0.252)\end{array}$ & $\begin{array}{c}0.257 \\
(0.118,0.444)\end{array}$ \\
\hline Etiocholanolone & $\begin{array}{c}0.105 \\
(0.0813,0.143)\end{array}$ & $\begin{array}{c}0.13 \\
(0.0818,0.18)\end{array}$ & $\begin{array}{c}0.112 \\
(0.088,0.202)\end{array}$ & $\begin{array}{c}0.189 \\
(0.136,0.24)\end{array}$ \\
\hline $\begin{array}{l}\text { Epietiocholano- } \\
\text { lone }\end{array}$ & $\begin{array}{c}0.00999 \\
(0.00917,0.0134)\end{array}$ & $\begin{array}{c}0.00574 \\
(0.00303,0.00628)\end{array}$ & $\begin{array}{c}0.00587 \\
(0.00486,0.00785)\end{array}$ & $\begin{array}{c}0.0112 \\
(0.0106,0.0127)\end{array}$ \\
\hline
\end{tabular}

Significance level $p<0.05$. Levels are shown as the median and quartiles in $n M / I$ 
Table 2 - Prediction of success in smoking cessation. Postmenopausal women smokers were divided into 3 groups according to success in smoking cessation: group $\mathbf{S +}$ are smokers successful in smoking cessation; group $\mathrm{S} \pm$ are smokers, who did not smoke for at least 6 weeks, but failed after that; group S- are smokers, who did not stopped smoking even after medical intervention

\begin{tabular}{lccc}
\hline Variable & $\mathrm{S}+$ & $\mathrm{S} \pm$ & $\mathrm{S}-$ \\
\hline Dehydroepiandrosterone & $3.32(2.69,5.15)$ & $5.53(4.77,7.92)$ & $7.92(6.04,8.69)$ \\
Androstenediole & $0.885(0.69,0.981)$ & $1.41(1.21,1.63)$ & $1.49(1.44,1.63)$ \\
Androstenedione & $2.49(1.65,3.54)$ & $5.55(4.73,7.12)$ & $5.85(5.3,7.96)$ \\
Testosterone & $1.08(0.608,1.17)$ & $2.29(1.31,2.53)$ & $2.53(2.42,2.69)$ \\
Dihydrotestosterone & $0.845(0.388,0.949)$ & $1.03(0.531,1.39)$ & $1.32(0.76,1.93)$ \\
Androsterone & $0.117(0.0755,0.205)$ & $0.643(0.345,0.775)$ & $0.775(0.763,0.853)$ \\
\hline
\end{tabular}

Significance level $p<0.05$. Levels are shown as the median and quartiles in $n M / I$

increase. Furthermore, there was a statistically significant decrease in SHBG after first 6 weeks of smoking cessation. The median levels of SHBG in the first sampling were $61 \mathrm{nmol} / \mathrm{l}$. After 6 weeks of smoking cessation the median levels were reduced to $32.1 \mathrm{nmol} / \mathrm{l}$ and stayed stable over the rest of the study. Changes in levels of C21 steroids were not significant. When searching for a possible biochemical marker of failure in smoking cessation, there was a unique parameter found. Higher androgen levels before the smoking cessation correlated with failure in smoking cessation (Table 2).

\section{Discussion}

Increased hyperandrogenemia or increased androgens to estrogens ratio in female smokers was reported by many authors (Van Voorhis et al., 1992; Barbieri et al., 2005; Manjer et al., 2005; Cochran et al., 2008; Cupisti et al., 2010) in all ages. This phenomenon was described already in very young smokers. Martin et al. (2001) conducted a pilot study focusing on relations among testosterone levels, carbon monoxide (CO) levels and current smoking, smoking in adolescence and in early puberty in a group of young women smokers. Testosterone levels correlated positively with cigarette smoking in the last 30 days, with $\mathrm{CO}$ levels, cigarette smoking in $7^{\text {th }}$ and $10^{\text {th }}$ grade of primary school and negatively correlated with the puberty onset age (Martin et al., 2001).

Several studies are focused on the influence of smoking on steroid production during menstrual cycle. In comparison to women non-smokers in the reproductive age, women smokers (moderate to severe addiction, i.e. $>10$ cigarettes/day) have $25-35 \%$ higher estrogen and progesterone levels in early follicular phase. Heavy smokers (>20 cigarettes/day) showed lower progesterone metabolites levels in luteal phase (Windham et al., 2005). Average androstenedione plasma concentration was higher in women smokers compared to women non-smokers 
but testosterone, estrone and estradiol levels did not differ (Longcope and Johnston, 1988).

In our previous study on premenopausal women we demonstrated that the chronic cigarette smoking (in comparison with permanent tobacco abstinence) augments serum androgens including some $5 \alpha / \beta$-reduced androstane metabolites but suppresses estradiol levels in the luteal phase, which may induce hyperandrogenism in the female smokers (Dušková et al., 2012).

Similar results showed studies in postmenopausal women. In study by Manjer et al. (2005) postmenopausal women smokers have higher testosterone concentrations compared to women non-smokers and the risk of this elevation rises with the number of cigarettes per day. Current smoking and increasing amount of current smoking were weakly associated with high androstenedione levels. However, these associations did not reach statistical significance. Also exsmoking was associated with high testosterone levels (Manjer et al., 2005). Also Cochran et al. (2008) demonstrated that current smokers had significantly higher androstenedione levels and a higher androgen-to-estrogen ratio than never smokers. Current smokers had significantly lower progesterone levels compared with never smokers. Former and current cigarette smokers had increased odds of experiencing hot flushes compared with never smokers (Cochran et al., 2008).

The data of Law et al. (1997) suggest a balance between higher androgen levels but lower rates of conversion of androgens to estrogens in smokers.

On the other side, Skałba et al. (2003) concluded that smoking have no significant effect on androgen concentration and SHBG changes in blood serum in postmenopausal women.

Taken together, testosterone is higher in women smokers throughout their lives. Our results are in concordance with previous studies reporting increased level of androgens.

There are only few reports on the effect of smoking cessation and circulating androgens (Lerman et al., 1993, Oncken et al., 2002). Oncken et al. (2002) found that six weeks of smoking abstinence produces reductions in SHBG, however they did not analyse testosterone. Ex-smoking was associated with higher testosterone levels in the study of Manjer et al. (2005).

In our previous study, we followed the group of premenopausal women after they discontinued smoking. We found that smoking discontinuation for 6 weeks leads to further increase of androgens (Dušková et al., 2011).

In postmenopausal women, we found increasing levels of androgens (testosterone, androsterone) during smoking cessation. When looking for factors, which could influence steroid levels after discontinuation of smoking, we found some possible explanations.

We considered the influence of smoking discontinuation and a nicotine influence itself in the nicotine replacement therapy. However, the androgen levels did not correlate with cotinine levels, therefore we rejected this hypothesis. Another 
possibility might be the effect of age as the women aged a year during the study. The effect of age was not demonstrated either. Another possibility could be a change in weight due to the smoking discontinuation. However, the changes in steroidogenesis did not correlate with the change in weight.

When trying to explain the increase of androgen levels after smoking discontinuation, it is useful to know the basal androgen levels prior to the start of smoking. All studies describe higher androgen levels in women smokers during their entire life but the entry levels before they become smokers are difficult to find. From this view, an interesting finding is the relation between higher testosterone levels in mothers who smoked during pregnancy and their daughters' smoking. Testosterone levels in mothers smoking during pregnancy correlated with daughters' smoking, however prenatal cotinine levels did not. The testosterone level in mothers smokers is probably a risk factor for daughters' smoking (Kandel and Udry, 1999). It seems that a higher testosterone level could be a predisposition for smoking.

Another theory is a chronic effect on steroidogenesis caused by smoking which produces irreversible changes in steroidogenesis. Their extent could play a role in maintaining dependence.

\section{Conclusion}

Smoking causes higher androgen levels in women. Our results indicate that smoking discontinuation leads to their further increase. There are several hypotheses explaining elevated levels of androgens after smoking cessation. We considered the influence of nicotine in nicotine replacement therapy. However levels of cotinine, which reflects nicotine income, do not correlate with levels of androgens. Neither gaining weight nor ageing process was associated with androgen levels. The question is what androgen levels women have before they start smoking and whether testosterone itself could play a role in development of tobacco addiction. Smokers may therefore have higher testosterone levels than non-smokers before starting smoking. We believe that, these levels are subsequently reduced by smoking and after cessation returned to its original concentrations. Another explanation for higher levels of testosterone is irreversibly affected steroidogenesis caused by chronic smoking.

\section{References}

Barbieri, R. L., Sluss, P. M., Powers, R. D., McShane, P. M.,Vitonis, A., Ginsburg, E., Cramer, D. C. (2005) Association of body mass index, age, and cigarette smoking with serum testosterone levels in cycling women undergoing in vitro fertilization. Fertil. Steril. 83(2), 302-308.

Cassidenti, D. L., Vijod, A. D., Vijod, M. A., Stanczyk, F. Z., Lobo, R. A. (1990) Short-term effects of smoking on the pharmacokinetic profiles of micronized estradiol in postmenopausal women. Am. J. Obstet. Gynecol. 163(6 Pt 1), 1953-1960.

Cochran, C. J., Gallicchio, L., Miller, S. R., Zacur, H., Flaws, J. A. (2008) Cigarette smoking, androgen levels, and hot flushes in midlife women. Obstet. Gynecol. 112(5), 1037-1044. 
Cupisti, S., Häberle, L., Dittrich, R., Oppelt, P. G., Reissmann, C., Kronawitter, D., Beckmann, M. W., Mueller, A. (2010) Smoking is associated with increased free testosterone and fasting insulin levels in women with polycystic ovary syndrome, resulting in aggravated insulin resistance. Fertil. Steril. 94(2), 673-677.

Dušková, M., Šimůnková, K., Hill, M., Velíková, M., Kubátová, J., Kancheva, L., Kazihnitková, H., Hruškovičová, H., Pospí̌ilová, H., Rácz, B., Salátová, M., Cirmanová, V., Králíková, E., Stárka, L., Pařízek, A. (2011) Cigarette smoking and progesterone and androgen metabolites in premenopausal women. Horm. Mol. Biol. Clin. Investig. 6, 259-264.

Dušková, M., Šimůnková, K., Hill, M., Velíková, M., Kubátová, J., Kancheva, L., Kazihnitková, H., Hruškovičová, H., Pospíšilová, H., Rácz, B., Salátová, M., Cirmanová,V., Králíková, E., Stárka, L., Pařízek, A. (2012) Chronic cigarette smoking alters circulating sex hormones and neuroactive steroids in premenopausal women. Physiol. Res. 61, 97-111.

Hill, M., Hampl, R., Lukáč, D., Lapčík, O., Pouzar,V., Šulcová, J. (1999) Elimination of cross-reactivity by addition of an excess of cross-reactant for radioimmunoassay of 17alpha-hydroxy-pregnenolone. Steroids 64, 341-355.

Hill, M., Pařizek, A., Kancheva, R., Dušková, M., Velíková, M., Kř̌̌ž, L., Klímková, M., Pašková, A., Žižka, Z., Matucha, P., Meloun, M., Stárka, L. (2010) Steroid metabolome in plasma from the umbilical artery, umbilical vein, maternal cubital vein and in amniotic fluid in normal and preterm labor.J. Steroid Biochem. Mol. Biol. 121, 594-610.

Kandel, D. B., Udry, J. R. (1999) Prenatal maternal effects of smoking on daughters' smoking: nicotine or testosterone exposure? Am. J. Public Health 89(9), 1377-1383.

Law, M. R., Cheng, R., Hackshaw, A. K., Allaway, S., Hale, A. K. (1997) Cigarette smoking, sex hormones and bone density in women. Eur. J. Epidemiol. 13(5), 553-558.

Lerman, C., Orleans, C. T., Engstrom, P. F. (1993) Biological markers in smoking cessation treatment. Semin. Oncol. 20(4), 359-367.

Longcope, C., Johnston, C. C. Jr. (1988) Androgen and estrogen dynamics in pre- and postmenopausal women: a comparison between smokers and nonsmokers. J. Clin. Endocrinol. Metab. 67(2), 379-383.

Manjer, J., Johansson, R., Lenner, P. (2005) Smoking as a determinant for plasma levels of testosterone, androstenedione, and DHEAs in postmenopausal women. Eur. J. Epidemiol. 20(4), 331-337.

Martin, C.A., Logan, T. K., Portis, C., Leukefeld, C. G., Lynam, D., Staton, M., Brogli, B., Flory, K., Clayton, R. R. (2001) The association of testosterone with nicotine use in young adult females. Addict. Behav. 26(2), 279-283.

Oncken, C., Prestwood, K., Cooney, J. L., Unson, C., Fall, P., Kulldorff, M., Raisz, L. G. (2002) Effects of smoking cessation or reduction on hormone profiles and bone turnover in postmenopausal women. Nicotine Tob. Res. 4(4), 451-458.

Rosenberg, M. J., Waugh, M. S., Stevens, C. M. (1996) Smoking and cycle control among oral contraceptive users. Am. J. Obstet. Gynecol. 174(2), 628-632.

Skałba, P., Wójtowicz, M., Sikora, J. (2003) Androgen and SHBG serum concentrations in late post-menopause women. Med. Sci. Monit. 9(3), CR152-CR156.

Thomford, P. J., Mattison, D. R. (1986) The effect of cigarette smoking on female reproduction. J. Ark. Med. Soc. 82(12), 597-604.

Van Voorhis, B. J., Syrop, C. H., Hammitt, D. G., Dunn, M. S., Snyder, G. D. (1992) Effects of smoking on ovulation induction for assisted reproductive techniques. Fertil. Steril. 58(5), 981-985.

Weigert, M., Hofstetter, G., Kaipl, D., Gottlich, H., Krischker, U., Bichler, K., Poehl, M., Feichtinger, W. (1999) The effect of smoking on oocyte quality and hormonal parameters of patients undergoing in vitro fertilization-embryo transfer. J. Assist. Reprod. Genet. 16(6), 287-293.

Windham, G. C., Mitchell, P., Anderson, M., Lasley, B. L. (2005) Cigarette smoking and effects on hormone function in premenopausal women. Environ. Health Perspect. 113(10), 1285-1290. 